\title{
Error element analysis and detection for BV75 CNC milling machine based on Ball-bar
}

\author{
Jinying Chen ${ }^{1}$, Xiaotie $\mathrm{Niu}^{2}$, Lijuan $\mathrm{Shi}^{3}$ \\ Beijing Vocational \& Technical Institute of Industry, Beijing 1000142,China \\ vegachjy@163.com
}

Keywords: CNC machine; Ball-bar; Geometry precision; detection; error

\begin{abstract}
Based on the error measurement principle of ball-bar, the errors of three different locations of BV75 CNC milling machine were measured by ball-bar. We can find out the main factors to influence the geometric accuracy of $\mathrm{CNC}$ machine tools that are the periodic error, lateral clearance and errors of perpendicularity and so on. The error producing reasons and influence for machining precision were analyzed, the solving measurements also proposed.
\end{abstract}

\section{Introduction}

The errors of CNC machine tool are divided into static errors and dynamic errors. The static errors mainly include the geometric error, the motion error, the thermal distortion error, etc. The dynamic errors include the spindle motion error, the vibration and the control error of the machine tool. The static error is about $70 \%$ of the total error of the machine [1], so it becomes the focus of the research.

As a tool of modern inspection, the ballbar can detect the machining accuracy, and the installation and operation of the $\mathrm{CNC}$ machine tools is simple and easy.

In this paper, the machining accuracy of BV75 NC machine tool is detected by using the ballbar, that cquisition between the ballbar rod length variation and error element mathematical model, combined with the direction of error sensitivity analysis, detection and separation of CNC machine tools, the main error element value of precision machine tool misalignment causes, and put forward solutions.

\section{BV75 three axis CNC milling geometric error element}

For the three axis NC milling machine space coordinate system. If the body has move along a certain coordinate system, it has six degrees of freedom in 3D space, as shown in Figure 1. At the same time, there are six geometric error components, such as the position of the three axes and the error of the straightness and the rotation error of the three axes. Therefore, there are 18 error components of three axis $\mathrm{CNC}$, and add three perpendicularity Error, we can get 21 geometric errors in three axis NC milling machine[2].

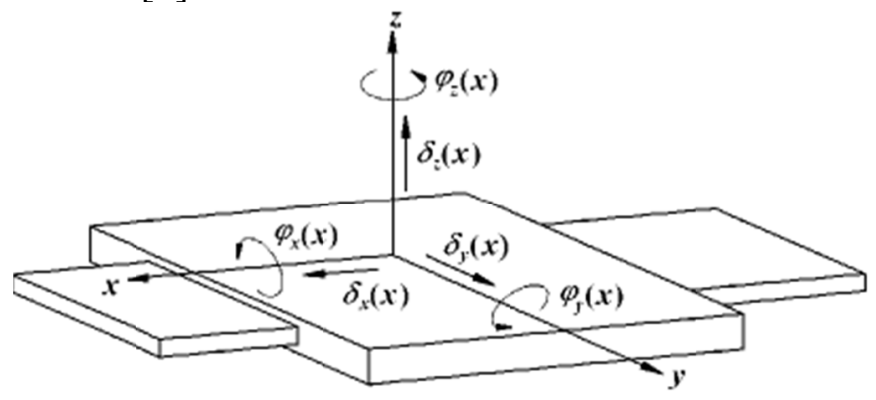

Figure 1 Error component of single axis motion

The 21 geometric errors are:

(1) There are six geometric errors for $\mathrm{X}$-axis: positioning error $\delta_{x}(x)$, straightness error of $\mathrm{y}$ is $\delta_{y}(x)$, straightness error of $\mathrm{z}$ is $\delta_{z}(\mathrm{z})$, elevation error $\varphi_{y}(x)$, rolling error $\varphi_{x}(x)$, deflection error $\varphi_{z}(x)$; 
(2) There are six error elements for Y-axis motion: positioning error $\delta_{y}(y)$, straightness error of $\mathrm{x}$ is $\delta_{x}(y)$, straightness error of $\mathrm{z}$ is $\delta_{z}(y)$, elevation error $\varphi_{x}(y)$, rolling error $\varphi_{y}(y)$, deflection error $\varphi_{z}(y)$;

(3) There are six error elements for Z-axis motion: positioning error $\delta_{z}(z)$, straightness error of $\mathrm{x}$ is $\delta_{x}(\mathrm{z})$, straightness error of $\mathrm{y}$ is $\delta_{y}(\mathrm{z})$, elevation error $\varphi_{x}(\mathrm{z})$, rolling error $\varphi_{z}(\mathrm{z})$, deflection error $\varphi_{y}(z)$;

(4) The error of perpendicularity between Y-axis, X-axis , Z-axis and is $\varphi_{x y}, \varphi_{x z}, \varphi_{y z}$. Subscript variable symbol of $\delta$ and $\varphi$ denoted error direction, that letters in brackets indicated the movement direction.

\section{Installation of Ballbar and make test plan}

We know that the ballbar runs a round trajectory in the plane of the machine tool. If there is no error, the running track of the ballbar should be the standard circle. When there are various errors in machine tools, the error of the machine tool can be obtained by analyzing the deviation between the running track of the ballbar and the standard circle[3].

The installation chart for the error measurement of the ballbar, as shown in Figure 2. When measuring the tee of magnetic precision and the work bench contact, and the other end of the tee contact with magnetic spindle[4]. The center of the two feference spherex coincide with each other in the center of the $\mathrm{X}$-Yreferende plane of the machine.

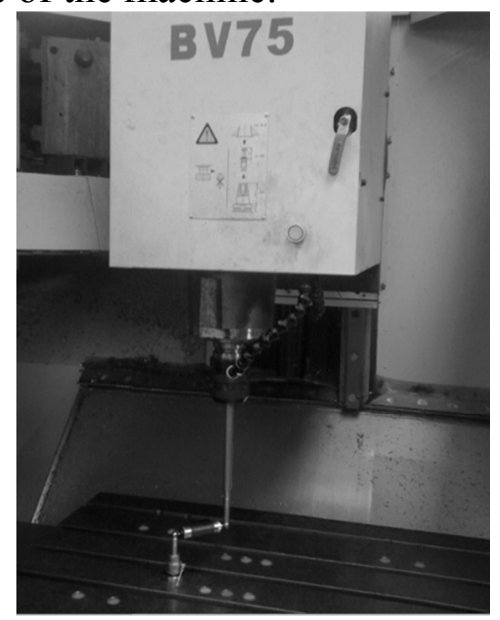

Figure 2 Experimental setup

BV75 CNC milling machine was installed Fanuc Systems and was manufactured in 2011. We used rapid detection model of Renishaw Ballbar20 and the QC20 -w wireless to test on the XY plane of circular error[5].

The test parameters are as follows:

(1) A $100 \mathrm{~mm}$ kinematic ballbar system complete with calibrated setting bar was used with the quick setting sleeve from the hardware.

(2)The machine was programmed to produce a 360 degree clockwise circle with a $100 \mathrm{~mm}$ radius. The start and end point was at 0 degree, then jump drive was 180 degree.

(3) Machine tool feed rate was $1500 \mathrm{~mm} / \mathrm{min}$ and distance of run is $700 \mathrm{~mm}$ times $500 \mathrm{~mm}$.

\section{Error detection and analysis of ballbar}

After the machine was flown to 1 hours, and we checked 3 points of the $\mathrm{x} \mathrm{y}$ plane for the machine tool. The coordinate position of the center of the workbench was $(\mathrm{X} 350, \mathrm{Y} 250) \mathrm{mm}$, the other two were $(X 150, Y 250) \mathrm{mm},(\mathrm{X} 550, \mathrm{Y} 250) \mathrm{mm}$, the detection results are shown in Figure 3,4,5. 


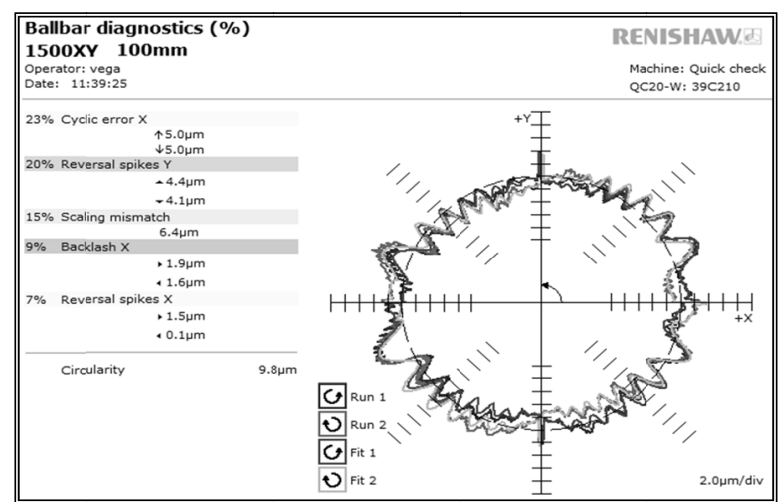

Figure 3 Coordinate position (X350,Y250)mm

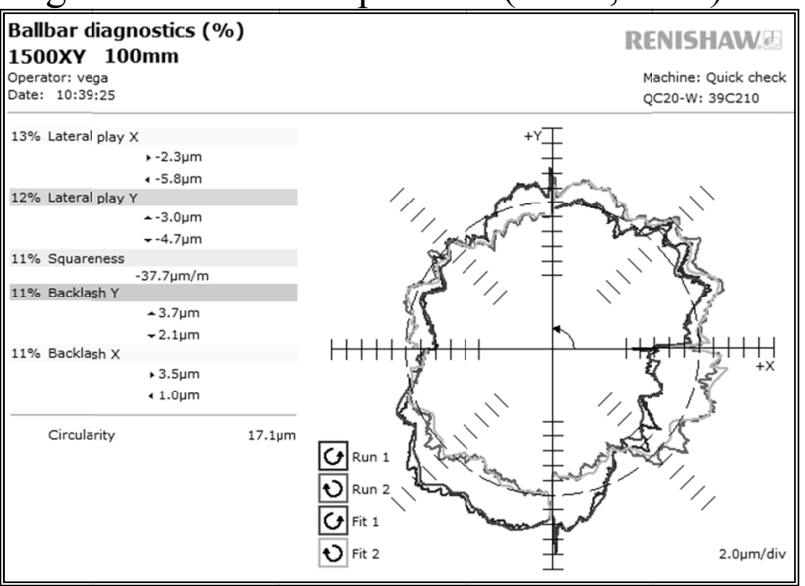

Figure 4 Coordinate position (X150,Y250)mm

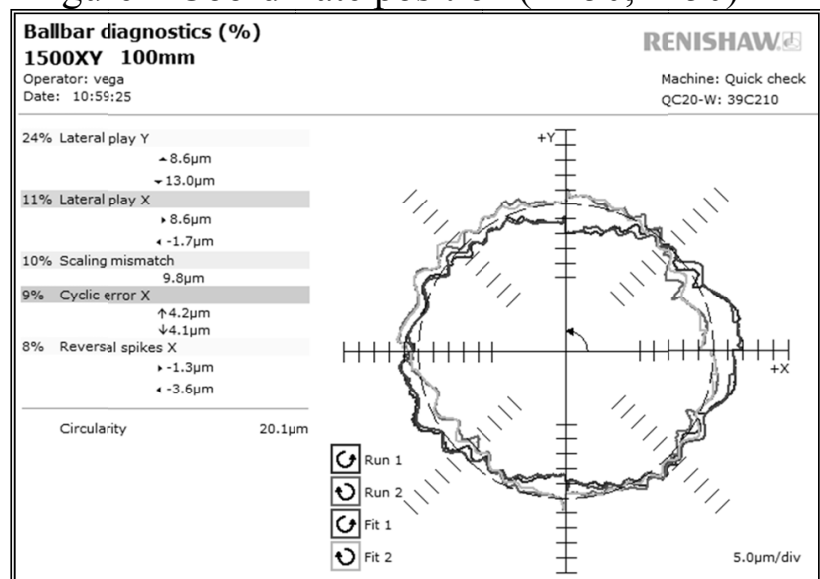

Figure 5 Coordinate position (X550,Y250)mm

Measured results were displaced on PC and PC for online data acquisition and analysis of the results. Analysis of data from figure 3,4,5. The main error source of the machine tool accuracy is periodic error of $x$ axis, lateral play y and reversal spikes $y$ and so on, as shown in Table 1 . These errors are constant error of the system.

Table 1 main errors and the percentage of the total errors

\begin{tabular}{|c|l|c|l|}
\hline Serial number & \multicolumn{1}{|c|}{ Error term } & percent & \multicolumn{1}{c|}{ value } \\
\hline 1 & Periodic error of X-axis & $23 \%$ & $+5 \mathrm{um}$ \\
\hline 2 & Lateral play Y & $24 \%$ & $-13 \mathrm{um}$ \\
\hline 3 & Reversal spikesY & $20 \%$ & $+4.4 \mathrm{um}$ \\
\hline 4 & Scaling mismatch & $15 \%$ & $9.8 \mathrm{um}$ \\
\hline 5 & Lateral play X & $13 \%$ & $-5.8 \mathrm{um}$ \\
\hline 6 & Perpendicularity error & $11 \%$ & $-37.7 \mathrm{um} / \mathrm{m}$ \\
\hline
\end{tabular}

Through the experimental data and images can be seen that have the following main errors of machine tool. 
(1) Periodic error of $\mathrm{X}$-axis

The periodic error was the periodic sine curve and changed along the graph frequency and amplitude, it was displayed on the $\mathrm{x}$ axis, as shown in figure 3 and 5.

First, we can check ball screw and adjust the installation of ball screw or position feedback system to eliminate periodic error. Second, we can check the balance of the machine and adjust the machine's balancing mechanism to eliminate the periodic error.

(2) Lateral play

Analysis of the images, the percentage of total errors of the lateral play of $x$-axis and $y$-axis are maximum. The main cause of the lateral clearance is the existence of gap or loosening in the rail of $\mathrm{CNC}$ machine tools. The main influence of lateral clearance is not round hole of CNC machining.The solution is to adjust or update machine guide rail to eliminate any gaps or loose.

(3) Reversal spikes Y

When the machine drive in axial one direction, then have to move backward to the opposite direction, its reverse motion is not smooth and appear a short pause. The main influence is that the arc interpolation tool path in a small steps, then reset the original trajectory.Solution is to test different kinds of feed rate, and find out reversal spikes in the minimum feed rate[6].

(4) Scaling mismatch

The proportion of the total error is $15 \%$, and the trajectory of the measurement is elliptical or peanut.From the figure 3 and 5, we can see that the tensile deformation along the $\mathrm{x}$-axis, causing shaft travel error, so in the xy plane within the circumference, $\mathrm{x}$-axis and y-axis running distance is not identical.The main influence of proportion mismatch error is the dimension error of the parts appearing.Solution is to check whether it is right of linear error compensation value then amended.

(5) Perpendicularity error

Analysis of the images acquisition, $\mathrm{x}$-axis and $\mathrm{y}$-axis perpendicularity error is negative that $\mathrm{x}$-axis and $y$ - axis angle is less than 90 degrees, without producing excessive wear, and the detection error direction consistent.The main influence of perpendicularity error is surface between vertical machining parts[7]. The solution is the xy axis should readjust the machine, and reduce the error of perpendicularity.

\section{Conclusion}

In this paper, we used the ballbar instrument to detect the errors of three different locations of BV75 CNC milling machine, and got the detection data of ballbar, and found out the main factors influencing geometry precision of machine tools, then analyzed the main factors influencing geometry precision of machine tools. The author has discussed and puted forward the method to recover the precision of machine tool. To use ballbar testing method that was adopted to establish the numerical control machine tool precision inspection and evaluation methods, so guide and improve the level of production of $\mathrm{NC}$ machine tools.

\section{Acknowledgements}

This work was supported by the Beijing Municipal Commission of Education Science and Technology Plan surfaces project support (PXM2014-014225-000007).

\section{References}

[1] A. C. Okafor, Y. M. Erenkin, Derivation of machine tool error models and error compensation procedure for three axes vertical machining center using rigid body kinematics, International Journal ,2002,48:149 160.

[2] Mou J, Liu C R: An adaptive methodology for machine tool error correction. ASME Transactions, Journal of Engineering for Industry, 1995, 117:389 399

[3] Samir Mekid: Precision machine design and error assessment, Crc Press, 2009, 2:70 71 
[4] Sartori S, Zhang G X: Geometric error measurement and compensation of machines. Annals of the CIRP, 1995, 44(2):599 609.

[5] Chen G Q, Yuan J X, Ni J. A : displacement measurement approach for machine geometric error assessment. International Journal of Machine Tools \& Manufacture,2001,41:149 160.

[6] HD. KwonandM. Burdekint, Development and application of a system for evaluating the feed-drive errors on computer numerically controlled machine tools Precision Engineering,1996, 19(3):135 143.

[7] Chen J S, Kou T W, Chiou S H: Geometric error calibration of multi-axis machines using an auto-alignment laser interferometer. Precision Engineering, 1999,23:245 256. 